\title{
INVESTIGATION OF PLATE WASTE IN UNIVERSITY REFECTORY
}

\author{
Melisa Ozbiltekin-Pala ${ }^{1}$ \\ Gülmüș Börühan ${ }^{2}$ iD
}

DOI: https://doi.org/10.31410/LIMEN.2020.379

\begin{abstract}
Food waste is a crucial global problem in the world. It is also a crucial issue for food services, consumers etc. Food is wasted throughout the entire food chain. At the consumer level, 35 percent of wasted food occurs. One of the main causes of food waste at consumer level is determined as "plate waste". Although, the issue needs sustainable solutions to decrease food waste, there is no permanent solutions in mass consumption places about food waste such as refectories, cafeterias. The aim of the study is to analyse the amount of plate waste in Yaşar University (YU) refectories in Izmir by observation method and to find ways of minimizing food waste in $Y U$, providing sustainability and contributing to the development of circular economy and raising awareness about food waste problem. For this research, the food waste at the YU refectories in Izmir was analysed by observation method. For 1-week observation study, a total of 3883 trays were examined throughout the Main campus and T blocks. It is determined that the biggest percentage is the main course and more than 50 percent of trays consist of waste in $Y U$ refectories.
\end{abstract}

Keywords: Food Waste, Mass Consumption, Observation.

\section{INTRODUCTION}

$\mathrm{F}$ ood waste is a critical issue for the world and the future. Food wastage is not about only food scarcity. According to Salihoglu (2018) food waste causes environmental impact such as unnecessary release of greenhouse gases or inefficient use of land and water. FAO estimates that $1 / 3$ of all food produced is lost or wasted emphasizes the importance of the problem. Food loss and waste (FLW) can occur throughout the food supply chain (FSC) (Godfray et al., 2010; Gustavsson et al., 2011). The best way to reduce environmental impacts is to decrease FLW (FAO, 2013b). FLW occur at several stages of the supply chain (FAO, 2011). Reducing edible food at the stage of production, post-harvest and processing is considered food loss (Godfray et al.,2010). Food wastes are occurred in developed countries, while food losses often occur in developing countries. Generally, 30-40\% of food is lost or wasted in all countries (Godfray, et al., 2010).

Food waste refers to food losses that occur during supply chain. Food waste is described by HLPE (2014) as the food, which is edible, discarded or left to be spoiled at the level of the product. Although the word "food loss" includes "food waste", it applies to losses in the FSC during the growth, post-harvest and processing stages (Godfray et al., 2010; Parfitt et al., 2010). Moreover, it is difficult to estimate FLW at various stages of the FSC. Several methods are used to examine FLW. At the country level, FLWs are calculated by applying specific loss factors to the different stages of the FSC (Kummu, 2012; Hall et al., 2009; Pradhan et al., 2014). 
In 2015, Turkey had more than 76 million inhabitants (TurkStat, 2015). Food industry and agricultural production are important sectors for the country's economy. One of the main problems is having enough food is not among the main problems in Turkey. Food is lost or wasted at the various stages of the FSC, from agricultural production to consumption, disposal or other removal methods (Lipinski et al., 2013).

Households have received considerable research and are biggest cause group of food waste in the consumption stage (Engström et al., 2004). Despite their potentially significant food waste generation, a more systematic study of total food service losses, especially in workplace and university cafeterias, hasn't received much attention (Gallardo et al., 2016). There could be many advantages to make analysis on food waste generation at universities. First, universities host people with experience and knowledge who can easily foster change in their environment. Second, food waste is usually a growing, if not the largest, fraction of waste generated on campuses (Lipinski et al., 2013). Although lots of universities have undertaken studies of planning of waste management, only a few have specifically focused on food waste generation and reduction methods (Abdelaal et al., 2019). Food wastes emerge on a larger scale, especially in public places, cafeterias and canteens. Therefore, the aim of this project is to analyse food waste in Yaşar University cafeterias and to offer solutions to reduce it with company of Fazla Gida. With the help of the project, to find permanent solutions of food waste are aimed.

\section{PROBLEM DEFINITION}

Global food demand is projected to increase $60-110 \%$ between 2005 (Alexandratos; Bruinsma, 2012; Pradhan, et al., 2013) and 2050 due to population growth. This increase is thought to help reduce FLW. In parallel, it is expected to reduce global warming since emissions from food production decreased (Foley, et al., 2011). Recently, one third of global food production (about 1.3 billion tons per year) is lost or wasted. (FAO, 2011). Preventing FLW can contribute to the conservation of resources used in food production and decrease the environmental impacts of agriculture, as well as increase local, regional and global food safety (Kummu, et al., 2012; Pradhan, et al., 2014).

One of the sectors where food waste is concentrated is food and beverage sector. Food and beverage sector have become one of the biggest sectors in the world due to its contribution to the economy and employment opportunities it creates (High Level Panel of Experts on Food Security and Nutrition, 2014). Moreover, in the food chain, the most waste occurs in consumption process. Consumers waste $35 \%$ of their food in households, restaurants and mass consumption places (refectories, hotels). While waste comes to the forefront at the consumption stage, losses during food preparation, spoilage due to incorrect preservation and cooking are also accompanied by this waste (Nguyen, 2018). However, food left on the plate should be investigated better than other losses and wastes. The plate waste which is a common cause of food waste means edible food left on the plate from the meal served (Williams and Warton, 2011).

Waste in refectories creates nutrients and economic losses for decision-makers, students, staff and is a loss for society due to its environmental impact. In order to prevent this loss, studies are carried out at different levels of education. Falasconi et al. (2015) search to food waste value in six schools from Verona (Italy) and $6525.35 \mathrm{~kg}$ food went to trash in 2008 to 2011 . By the way, surveyed 500 students in University of California, Berkeley about food waste. 210 students $(43 \%)$ did not eat $\% 30$ per cent food tray and number of $\% 9$ students did not eat more 
than $\% 50$ per cent food tray (Lam, 2010). Sarjahani et al. (2009) collect food waste value about 2 weeks (10 days with Monday through Friday) in Virginia Polytechnic Institute and State University (Virginia Tech); Calculated 12.090 kilos food waste from breakfast, lunch and dinner.

There may be many advantages to addressing research efforts in the case of food waste in universities. First, universities are important for hosting individuals with experience and knowledge. Second, food waste is a large waste generated generally on campuses (Gallardo et al., 2016). While many universities implement practices for waste management plan studies (Gallardo et al., 2016), only a few add solutions for the formation and mitigation (Kim and Morawski, 2012).

Yasar University is one of the most important universities in İzmir with more than 600 staff (academic and administrative personnel) and more than 10 thousand students. Yasar University is one of 205 other universities in Turkey so universities can organize food wastes and can create economic and environmental benefits for the world. Yasar University is located in two separate locations: main campus and T block. Therefore, there are 2 separate refectories on the main campus and T block. According to data which are collected from food company providing food to Yasar University, the total number of people eating at Yasar University main campus and T block cafeterias was 15617 in September with 10844 staff and 4773 students. Moreover, according to data the number was 20957 in October with 17637 staff and 3320 students and it was 19993 in November with 12585 staff and 7408 students.

Furthermore, according to the study, Yaşar University' refectory produce food waste with 3883 trays $(57 \%)$ in 1 week (Monday through Friday). However, the results showed that Yaşar University refectory is facing a huge food waste problem. Therefore, sustainable and circular solutions are needed to minimize food waste occurs in the refectory of the university.

\section{LITERATURE REVIEW}

In this study, literature review is organized under 3 main headings; food surplus, food waste and circular economy. Firstly, food surplus is explained in detail.

\section{FOOD SURPLUS}

Food surplus is a global issue. Furthermore, it is a key index to compare how different groups and societies have handled shortage and abundance problems, climatic variation and power relations in the past. According to Raak et al. (2017) "Inflated order to make the shelves look full" is important for companies because companies think to necessity of loaded racks for consumers. Moreover, food surplus is eatable, dumped food that is quit deliberately, has been extinguished from sale from e.g., a grocery store, or else fails to be consumed due to several causes. Food surplus changes food waste when it becomes invincible (Jurgilevich et al., 2016). Food surplus is generally about physical appearance of food in retail and institutional markets (Thyberg and Tonjes, 2016). In the future, it is expected that food surplus in most countries will move to grow due to increased demand for food. It is expected to increase in global food surplus around $850 \mathrm{kcal} / \mathrm{cap} /$ day by 2050 (Hiç et al., 2016). Compared with the required amount, the available food's growth rate will be more outstanding in the country of transit. The growth rate of available food compared to the required amount will be more prominent in the transition countries. The one of the important points of food waste is overproduction which is related with food surplus. On the other perspective, it is noted that overproduction is not a huge 
problem for some products which have long shelf-lives such as juice, cheese, biscuits, convenience food. These products can be donated or redistributed. There are motivations based on environment and social, and for donors, economic benefits can be raised. Apart from products with a long shelf-life, the food produced should be sold or donated as soon as possible, but it is generally expected to be sold in stores. However, redistribution processes can be damaged because of hygiene regulations and logistical limitations (Raak et al.,2017). One of the functions of "degree of recoverability" is the transition from surplus food to food waste. In the following section, food waste is explained in detail.

\section{FOOD WASTE}

Food waste is an important issue for our future and this issue start from our environment. Peng and Pivato (2017) states that food waste occurs because of discharged, lost, degraded, or contaminated of food for human consumption (Girotto et al 2015).

The reasons for food waste in developed and developing countries are related to consumer behaviour and lack of communication between the parts of the supply chain. Foods can be waste because of quality which are rejected cause of do not fit with required appearance or shape (Girotto et al., 2015). The reasons of food waste in undeveloped countries are mostly dependent on financial, administrative and technical limitations, insufficient storage and cooling facilities, poor infrastructure, poor packaging and marketing systems (Girotto et al., 2015). The reduction in the number of intermediaries and dealers can importantly contribute to the reduction of food waste. In this way, losses induced by wholesale or retail may be reduced (Kiss et al., 2019).

Global food waste amounts to nearly $25 \%$ of all food produced. Production part represents 24 $30 \%$ of global food waste, while post-harvest stage shows for $20 \%$ and consumption for 30 $35 \%$. After all, fruits and vegetables are the largest source of food waste (44\%), follow up by roots and tubers (20\%) (Vilariño et al., 2017).

By considering literature review, there are many studies about food waste. To start with Baglioni (2017) analysed government and third-party sector operations on food waste and redistribution in Lombardy (Italy) and Baden- Wurttemberg (Germany). According to his study, government sides use tax tool for managing to food waste and non-profit organisations support private companies for their needs and increase their reputation like government about food waste. Moreover, Bhatt (2018) studied on recycling food problem and the study covers value-added surplus products have potential for creating a new type of food (Bhatt, 2018). In addition, Buzby (2009) analysed that annual food waste value in supermarket between 2005 and 2006. This study found average food waste value 11.4 percent for fruit, 9.7 per cent for vegetables and 4.5 per cent for meat types in supermarket. The objective of the study is to calculate food waste value about food categories for creating innovative packaging to prolong shelf life.

Garrone et al., (2014) focused on the multifaceted concept of FSC maintainability by showing a show of excess food production and administration, which includes the coordinates FSC (i.e. trade, natural and social players). Moreover, Borrello et al., (2017) state that mechanical society is confronting disturbing worldwide problems caused by the impacts of human exercises on the environment. This study states that numerous consumers are willing, on the off chance that adequately compensated, to be committed to support in circular circle. In addition, Franco et al. (2017) analysed a significant portion of the products created for human consumption turn 
into waste in the world is presented as connected environmental, economic issues and social based on existing data and reviewed literature. The writers specify the different food waste models and challenges faced by different areas around the world. Also, the food value chain analysed from agricultural production down to household consumption. The environmental and socio-economic impacts of FLW are analysed based on reviewed life cycle assessments. Finally, it reflects on the main challenges for performing strategies to reduce FLW. Moreover, Kiss et al. (2019) state that according to deep research, short supply chain is related to sustainability and cyclical economy and it also considers the effect of short supply chain on circular economy and sustainability. In their research, the authors focus on the issue that the short supply chain is linked to cyclicity and sustainability; environmental load (transport, production method, emission), health, food quality, consumer behaviour, producer-consumer relations and local economy.

Furthermore, Parfitt et al. (2010) discussed that post-harvest losses and household wastes in developing and developed countries were addressed and interviews were conducted with postprocurement experts to find a solution and the work was aimed at preventing the postproduction from the supply chain to household wastes. Girotto et al. (2015) state that as a result of research, it is known that waste is increasing in all stages of production and consumption from collection to disposal. Sustainability is the most important solution, and it includes everyone in the industrial sectors, from producers to distributors. One of the most appropriate solution is to donate the re-donable waste. In addition, Raak et al. (2017) state that based on this scientific literature survey, the researchers gathered with experts from 13 German food processing companies and discussed at what stages the problems of food waste were encountered and it was tried to find solutions with the interviewed representatives in order to minimize the formation of food waste. Also, Mourad (2016) states that as a result of approximately 120 interviews and many evaluations in France and California, especially in these regions, it seeks to manage in terms of sustainable production and consumption in general and solutions for recycling.

Food waste important for companies because companies do not have knowledge to organize food waste. Food waste organization must be controlled by companies because at the end of day food waste organization can change. Companies cannot control the food waste problem rightly so Food Recovery Hierarchy help to companies to take maximum benefit from food surplus and food waste.

\section{CIRCULAR ECONOMY}

Circular economy aims to transforms traditional linear supply chains with networks based on "waste=food" (Borello et al., 2017). The circular economy approach consists of the idea of recycling towards upcycling, which represents to any process that can convert waste to a higher value. To sum up; the circular economy is planned to "waste one's resources". For this reason, a circular economy can promote more critical transformations (Ellen MacArthur Foundation, 2012). To illustrate, new circular economy models consider waste generated throughout the linear life cycles. The need to move to a circular economy has become a part of the road map of policy makers and strategic plans of industries and businesses (Ghisellini, 2016).

After all, there are still some challenges facing the sustainability of the transition to a circular economy (Borrello et al.,2018). Some of these challenges are the role of society and consumers. Consumers are the last stage in their supply chain in a linear economy. Borello et al. (2017) states that their contribution is only purchase of products. For this reason, they are uninvolved 
and ignorant in their state of middle people among retailers and waste collection. Food waste is the most important thing which consumers could participate to circular economy.

An important point in sustainable consumption and production is to decrease of food waste. Defined conventional operation of food waste can lead to environmental, economic, and social problems (Lozano et al., 2014). There are more sustainable or profitable administration options like reuse and, for example, sugars can be synthesized from food waste (Kiss et al., 2019). Circular economy hierarchy consist of " 3 Rs"; reduce, re-use and recycle of waste (Kiss et al., 2019). In the upper part of our scheme, as much production as possible is avoided. In the second part of our scheme, food that is close to the potential of being garbage is re-use for human needs. In the third part of the scheme, recycled food is used as fertilizer and animal feed. In the recovery section, inevitable food wastes are re-processed to gain energy. The last section is the disposal of unused products (Lozano et al., 2014). The principles of the circular economy concerning food chains include minimising waste and surplus, reusing food, food recycling, and supporting more diverse and effective. These approaches can contribute to the avoiding of food waste and can help to achieve the goals of the circular economy (Kiss et al., 2019).

If food wastes cannot be recovered under the circular economy heading, water resources as one of the most important consequences will affect the production of food if in water resources will be a problem. Production of wasted food cause global greenhouse emissions and it occurs to squander of usable water sources. FLW also occurs to climate change estimated $8 \%$ in the world. All the FLW doesn't have an equal impact to the environment. In solution to environmental problem companies must be paying attention to higher shares of caloric losses, but also paying attention to all the impacts of each good (Franco et al., 2017).

\section{METHODOLOGY}

In this study, observation method was applied to justify and specify critical status of waste generated in Yaşar University refectories. Observation method has allowed to see the total number of people eating at the university refectories during the research period and how many foods became waste at the end of the lunch time.

Due to the fact that the wastes produced in the university refectories cannot be evaluated, an observation study was conducted simultaneously in the refectories of Main campus and $\mathrm{T}$ blocks of Yaşar University. This study was carried out in order to obtain the waste rates in the cafeteria between from 11:30 am 14:30 pm and between 25-29 November 2019. At the end of the 1-week study, a total of 3883 trays were examined throughout the Main campus and T blocks. 3254 of these trays were observed in Main Campus and 629 of them were observed in $\mathrm{T}$ block. According to the observation, results are explained below respectively.

According to results in 1-week period, totally 2729 amount of food samples became waste in main block of Yaşar University. Based on the results, it is seen that the biggest percentage is the main course. The rate of this is $26 \%$. So, based on the results of a one-week observation, most people leave waste at their main course. This is followed by $21 \%$ salads. However, the helper meal (rice/pasta) comes with a rate of $17 \%$, followed by bread with $10 \%$, dessert and with $9 \%$, soup with $8 \%$, appetizer with $7 \%$ and the type of food with at least $2 \%$ left as yoghurt, and finally fruit is not waste. Moreover, the number of trays was analysed. According to results, 1814 trays contain waste and 1440 trays do not contain waste in the main campus. Approximately $56 \%$ of the 3254 trays observed contain waste. As a result of the observations, 
it is seen that it contains at least 1 waste in $56 \%$ of the university refectories in main campus. This ratio means that there is a serious waste in there.

Furthermore, the same observation is applied for T block's refectory. According to results, totally 605 amounts of food samples became waste at dinner time for 1 -week period. According to results, it is seen that the biggest percentage is the main course. The rate of this is $29 \%$. So, based on the results of a one-week observation, most people leave waste at their main course. This is followed by $21 \%$ salads. Afterwards, the helper meal (rice / pasta) comes with a rate of $18 \%$, followed by dessert with $8 \%$, bread and soup with $7 \%$, appetizer with $5 \%$, yoghurt with $3 \%$ and fruit with $2 \%$. Moreover, the number of trays observed were analysed in $\mathrm{T}$ block refectory. According to observation, 411 trays contain waste and 218 trays do not contain waste in T block. Approximately $65 \%$ of the 629 trays observed contain waste. As a result of the observations, it is seen that it contains at least 1 waste in $65 \%$ of the university refectories. This ratio indicates that there is a serious waste.

By considering whole Yaşar University refectories, the critical waste status can be seen. At the end of the observations, totally 3334 amounts of food became waste and junked. Generally, main dish, rice/pasta and salad are observed as the most wasted type of food in Yaşar University.

Graph 1. Waste Rate by Yaşar University for each type of food

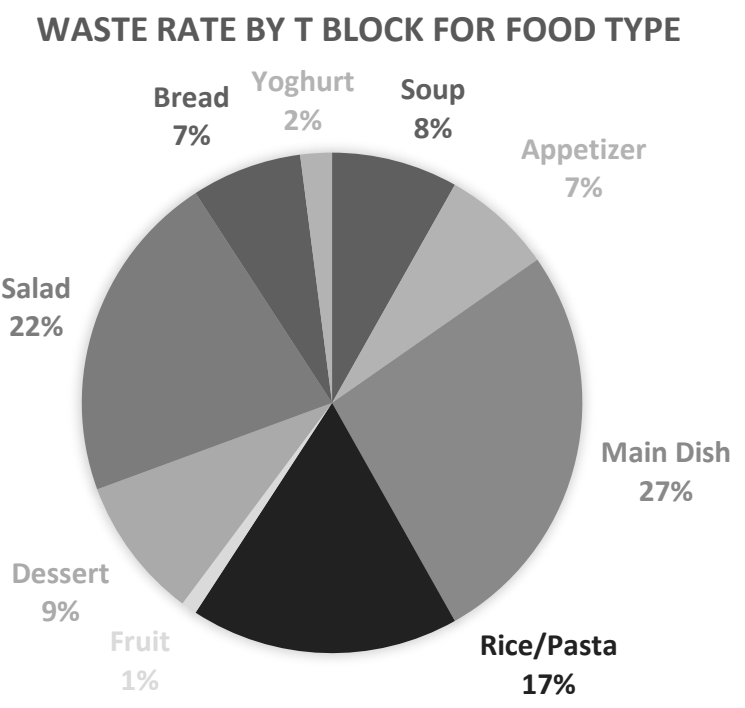

Looking at the Graph 1, it is seen that the biggest percentage is the main course. The rate of this is $26 \%$. So, based on the results of a one-week observation; most people leave waste at their main course. This is followed by $21 \%$ salads. Afterwards, the helper meal (rice / pasta) comes with a rate of $17 \%$, followed by dessert and bread with $9 \%$, and soup comes with $8 \%$, appetizer with $7 \%$, yoghurt with $2 \%$ and the type of food with at least $1 \%$ left as fruit. Moreover, according to the results, 3334 trays contain waste and 1658 trays do not contain waste in whole Yaşar University refectories for 1-week period. Approximately $57 \%$ of the 3883 trays observed contain waste. As a result of the observations, it is seen that it contains at least 1 waste in $57 \%$ of the university cafeterias. This ratio shows that there is a serious waste. 


\section{CONCLUSION AND FURTHER RESEARCH}

Recently, food surpluses lead to food waste. The places that cause the most food waste are universities, hospitals and hotels. According to the research, it is seen that food wastes are mostly caused by "food on a plate" behaviour by consumers. Within the scope of this study, Yaşar University refectories providing food service to an average of 20 thousand people each month were discussed. After literature review was done, an observation of level of food waste which are created in refectories at Yasar University was conducted. All these searches and observations show that especially Yaşar University is facing with "food waste problem" and food waste is really important in human life and it really affects to create big problems in the environment, human health, sustainability, etc.

In this study, firstly it is aimed to analyse the amount of plate waste in the university refectory and then to create awareness about the food waste problem and to find sustainable and cyclical solutions to this problem in Yaşar University' refectory. After the observation method, it is planned to conduct face-to-face interview to measure food waste perceptions of consumers who are students, academicians and administrative staff of Yaşar University for the further research. Furthermore, based on observation results, we cooperated with Fazla Gida, which provides digital platform for the companies in order to reduce food waste and to ensure the evaluation of the waste generated. After meetings with Fazla Gida, proposed flow system for plate waste will be prepared for university refectories This proposed flow will enable the reduction of food waste in refectories and capacity planning for preparation of food at the preparation stage of food. We believe that, our cooperation with Fazla Gida will continue to find sustainable solutions of food waste within the framework of circular economy.

\section{REFERENCES}

Abdelaal, A. H., McKay, G., \& Mackey, H. R. (2019). Food waste from a university campus in the Middle East: Drivers, composition, and resource recovery potential. Waste Management, 98, 14-20. https://doi.org/10.1016/j.wasman.2019.08.007

Alexandratos, N. \& Bruinsma, J. World Agriculture Towards 2030/2050: The 2012 Revision Ch. 4 (ESA/12-03, FAO, 2012)

Baglioni, S., De Pieri, B., \& Tallarico, T. (2017). Surplus food recovery and food aid: The pivotal role of non-profit organisations. Insights from Italy and Germany. VOLUNTAS: International Journal of Voluntary and Non-profit Organizations, 28(5), 2032-2052. https://doi.org/10.1007/s11266-016-9746-8

Bhatt, S., Lee, J., Deutsch, J., Ayaz, H., Fulton, B., \& Suri, R. (2018). From food waste to value-added surplus products (VASP): Consumer acceptance of a novel food product category. Journal of Consumer Behaviour, 17(1), 57-63. https://doi.org/10.1002/cb.1689

Borrello, M., Caracciolo, F., Lombardi, A., Pascucci, S., \& Cembalo, L. (2017). Consumers' perspective on circular economy strategy for reducing food waste. Sustainability, 9(1), 141. https://doi.org/10.3390/su9010141

Buzby, J. C., Wells, H. F., Axtman, B., \& Mickey, J. (2009). Supermarket loss estimates for fresh fruit, vegetables, meat, poultry, and seafood and their use in the ERS loss-adjusted food availability data (No. 1476-2016-120929).

Ellen Macarthur Foundation (2012). Towards the Circular Economy. Retrieved from: https://www.ellenmacarthurfoundation.org/assets/downloads/publications/EllenMacArthur-Foundation-Towards-the-Circular-Economy-vol.1.pdf

(Accessed 26.09.2020). 
Engström, R., \& Carlsson-Kanyama, A. (2004). Food losses in food service institutions Examples from Sweden. Food policy, 29(3), 203-213. https://doi.org/10.1016/j.foodpol.2004.03.004

Falasconi, L., Vittuari, M., Politano, A., \& Segrè, A. (2015). Food waste in school catering: An Italian case study. Sustainability, 7(11), 14745-14760. https://doi.org/10.3390/su71114745

FAO (2011). Global Food Losses and Food Waste Extent Causes and Prevention. at Interpack2011 Retrieved from:

http://www.fao.org/fileadmin/user_upload/suistainability/pdf/Global_Food_Losses_and_Foo d_Waste.pdf (Accessed 03.05.2020).

FAO (2013). Toolkit: Reducing the Food Wastage Footprint. Food Agriculture Organization Retrieved from: http://www.fao.org/3/i3342e/i3342e.pdf (Accessed 10.05.2020).

Gallardo, A., Edo-Alcón, N., Carlos, M., \& Renau, M. (2016). The determination of waste generation and composition as an essential tool to improve the waste management plan of a university. Waste management, Vol. 53, 3-11. https://doi.org/10.1016/j.wasman.2016.04.013

Garrone, P., Melacini, M., \& Perego, A. (2014). Opening the black box of food waste reduction. Food policy, Vol.46, 129-139. https://doi.org/10.1016/j.foodpol.2014.03.014

Ghisellini, P., Cialani, C., \& Ulgiati, S. (2016). A review on circular economy: the expected transition to a balanced interplay of environmental and economic systems. Journal of Cleaner Production, Vol.114, 11-32. https://doi.org/10.1016/j.jclepro.2015.09.007

Girotto, F., Alibardi, L., \& Cossu, R. (2015). Food waste generation and industrial uses: a review. Waste Management, Vol. 32-41. https://doi.org/10.1016/j.wasman.2015.06.008

Godfray, H. C. J., Beddington, J. R., Crute, I. R., Haddad, L., Lawrence, D., Muir, J. F., ... \& Toulmin, C. (2010). Food security: the challenge of feeding 9 billion people. Science, 327(5967), 812-818. https://doi.org/10.1126/science.1185383

Gustavsson, J., Cederberg, C., Sonesson, U., \& Emanuelsson, A. (2013). The methodology of the FAO study: Global Food Losses and Food Waste-extent, causes and prevention"FAO, 2011.

Hiç, C., Pradhan, P., Rybski, D., \& Kropp, J. P. (2016). Food surplus and its climate burdens. Environmental Science \& Technology, 50(8), 4269-4277. https://doi.org/10.1021/acs.est.5b05088

High Level Panel of Experts on Food Security and Nutrition (HLPe). (2014). Food Losses and Waste in the Context of Sustainable Food Systems. A Report by the High Level Panel of Experts on Food Security and Nutrition of the Committee on World Food Security. Hlpe Report, (June), 1-6.

https://ik.yasar.edu.tr/ (Accessed 23.03.2020).

Jurgilevich, A., Birge, T., Kentala-Lehtonen, J., Korhonen-Kurki, K., Pietikäinen, J., Saikku, L., \& Schösler, H. (2016). Transition towards circular economy in the food system. Sustainability, 8(1), 69. https://doi.org/10.3390/su8010069

Kim, K., \& Morawski, S. (2012). Quantifying the impact of going trayless in a university dining hall. Journal of Hunger \& Environmental Nutrition, 7(4), 482-486. https://doi.org/10.1080/19320248.2012.732918

Kiss, K., Ruszkai, C., \& Takács-György, K. (2019). Examination of Short Supply Chains Based on Circular Economy and Sustainability Aspects. Resources, 8(4), 161. https://doi.org/10.3390/resources8040161

Kummu, M., De Moel, H., Porkka, M., Siebert, S., Varis, O., \& Ward, P. J. (2012). Lost food, wasted resources: Global food supply chain losses and their impacts on freshwater, 
cropland, and fertiliser use. Science of the Total Environment, Vol. 438, 477-489. https://doi.org/10.1016/j.scitotenv.2012.08.092

Lam, Y. (2010). Why do UC Berkeley students waste food at dining halls. University of California Berkeley.

Luecke, L. (2015). Haste to No Waste: A Multi-Component Food Waste Study in a University Dining Facility Dining Facility. Proceedings of The National Conference On Undergraduate Research (NCUR) 2015 Eastern Washington University, Cheney, WA

Mourad, M. (2016). Recycling, recovering and preventing "food waste": competing solutions for food systems sustainability in the United States and France. Journal of Cleaner Production, Vol. 126, 461-477. https://doi.org/10.1016/j.jclepro.2016.03.084

Nguyen Khanh Linh. (2018). Food waste management in the hospitality industry Case study: Clarion Hotel Helsinki. Haaga-Helia University of Applied Sciences, 1-63. Retrieved from https://www.theseus.fi/bitstream/handle/10024/142528/NGUYEN_KHANH LINH.pdf?sequence $=1 \&$ isAllowed=y (Accessed 04.04.2020)

Parfitt, J., Barthel, M., \& Macnaughton, S. (2010). Food waste within food supply chains: quantification and potential for change to 2050. Philosophical transactions of the royal society B: biological sciences, 365(1554), 3065-3081. https://doi.org/10.1098/rstb.2010.0126

Peng, W., \& Pivato, A. (2019). Sustainable management of digestate from the organic fraction of municipal solid waste and food waste under the concepts of back to earth alternatives and circular economy. Waste and Biomass Valorization, 10(2), 465-481. https://doi.org/10.1007/s12649-017-0071-2

Raak, N., Symmank, C., Zahn, S., Aschemann-Witzel, J., \& Rohm, H. (2017). Processing-and product-related causes for food waste and implications for the food supply chain. Waste Management, Vol. 61, 461-472. https://doi.org/10.1016/j.wasman.2016.12.027

Salihoglu, G., Salihoglu, N. K., Ucaroglu, S., \& Banar, M. (2018). FLW management in $\begin{array}{llll}\text { Turkey. Bioresource } \quad \text { Technology, } & \text { 88-99. }\end{array}$ https://doi.org/10.1016/j.biortech.2017.06.083

Sarjahani, A., Serrano, E. L., \& Johnson, R. (2009). Food and non-edible, compostable waste in a university dining facility. Journal of Hunger \& Environmental Nutrition, 4(1), 95102. https://doi.org/10.1080/19320240802706874

Thyberg, K. L., \& Tonjes, D. J. (2016). Drivers of food waste and their implications for sustainable policy development. Resources, Conservation and Recycling, 106, 110-123. https://doi.org/10.1016/j.resconrec.2015.11.016

TurkStat, 2015. Turkey in Statistics 2015. Turkish Statistical Institute, ISBN 978-975-196546-2. Publication Number: 4431.

Vilariño, M. V., Franco, C., \& Quarrington, C. (2017). FLW reduction as an integral part of a circular economy. Frontiers in Environmental Science, 5, 21. https://doi.org/10.3389/fenvs.2017.00021

Williams, P., \& Walton, K. (2011). Plate waste in hospitals and strategies for change. e-SPEN, the European e-Journal of Clinical Nutrition and Metabolism,6(6), e235-e241. https://doi.org/10.1016/j.eclnm.2011.09.006

Williams, P., \& Walton, K. (2011). Plate waste in hospitals and strategies for change. E-SPEN, 6(6). 